\title{
Weight reduction and pioglitazone ameliorate polycystic ovary syndrome after removal of a Sertoli-stromal cell tumor
}

This article was published in the following Dove Press journal:

International Journal of Women's Health

22 November 2012

Number of times this article has been viewed

\author{
Tsuyoshi Baba' \\ Toshiaki Endo' \\ Keiko Ikeda' \\ Ayumi Shimizu' \\ Miyuki Morishita' \\ Yoshika Kuno' \\ Hiroyuki Honnma ${ }^{2}$ \\ Tamotsu Kiya ${ }^{3}$ \\ Shin-ichi Ishioka' \\ Tsuyoshi Saito' \\ 'Department of Obstetrics and \\ Gynecology, Sapporo Medical \\ University, Sapporo, ${ }^{2}$ Asada Ladies \\ Clinic, Kasugai, Aichi, ${ }^{3}$ Ena Ladies \\ Clinic, Ishikari, Hokkaido, Japan
}

Correspondence: Tsuyoshi Baba

Department of Obstetrics and

Gynecology, Sapporo Medical

University, South I West 16, Sapporo,

Hokkaido, 060-8543 Japan

$\mathrm{Tel}+81116112111$

Fax +8II I6I40860

Email tbaba@sapmed.ac.jp

\begin{abstract}
This report presents an unusual case of Sertoli-stromal cell tumor and polycystic ovary syndrome successfully treated with weight reduction and an insulin-sensitizing agent. A 22-year-old woman, gravida 0 , para 0 , visited our hospital for the first time with a 12-year history of secondary amenorrhea and hypertrichosis. Transvaginal ultrasonography revealed a solid tumor in the right ovary. Right salpingo-oophorectomy was performed and pathological examination confirmed a Sertoli-stromal cell tumor. The patient's serum androgen levels declined postoperatively, but remained above normal. Pioglitazone treatment for 6 months also significantly reduced serum androgen levels, but they still remained above normal. However, after losing $12 \mathrm{~kg}$ of body weight, the patient's serum androgen levels declined to normal, and spontaneous menstruation became regular. Weight reduction with pioglitazone is an effective means of treating hyperandrogenism.
\end{abstract}

Keywords: etiology, hyperandrogenism, pioglitazone, polycystic ovary syndrome, Sertolistromal cell tumor, weight reduction

\section{Introduction}

Hyperandrogenism is a condition in which androgen excess leads to ovulation disorders and hirsutism. The causes of hyperandrogenism in women are varied; polycystic ovary syndrome (PCOS) is the most frequent cause, with late onset congenital adrenal hyperplasia, Cushing's syndrome, and androgen-secreting tumors of the ovaries and adrenal glands occurring in rare instances. The symptoms of these disorders are similar in many respects, and the presence of multiple sources inducing hyperandrogenism is usually an unexpected circumstance.

Sertoli-stromal cell tumors of the ovary are a heterogeneous group of benign and malignant tumors that account for less than $1 \%$ of primary ovarian tumors. ${ }^{1}$ They are a type of sex cord-stromal tumor and secrete various androgens. The related hyperandrogenism can be cured by complete removal of the tumor; however, androgen-secreting tumors such as this one are thought to sometimes cause a secondary PCOS due to exposure of the ovary to high levels of androgens at puberty. ${ }^{2}$ In such cases, tumor resection, by itself, may not ameliorate the hyperandrogenism completely. Instead, sustained hyperandrogenemia may persist in the absence of the tumor.

Here we report a case of secondary amenorrhea and hirsutism that developed after menarche. A Sertoli-stromal cell tumor of the right ovary was removed, but the patient's androgen levels did not normalize completely. Thorough studies revealed her PCOS status, which required an insulin-sensitizing agent and weight loss to resolve. 


\section{Case report}

A 22-year-old Japanese woman, gravida 0 , para 0 , was referred to us by the clinic at which she first presented with a 12-year history of amenorrhea and hypertrichosis of the face, vulva, mons pubis, and thigh. She did not show male-pattern baldness because Japanese patients with PCOS usually do not have severe virilization. In other respects, her medical history was uneventful. She left her secondary amenorrhea untreated for a long time because she was socially withdrawn, homebound, and no family member noticed her abnormality. Her menarche was at 10 years of age, but menstruation never occurred after that. The patient noticed growth of a beard and thickening of her pubic hair. Her appearance was obese; her height was $158 \mathrm{~cm}$ and her body weight was $65 \mathrm{~kg}$ (body mass index $26.0 \mathrm{~kg} / \mathrm{m}^{2}$ ). The patient's endocrine and metabolic profiles are presented in Tables 1 and 2 . The assay type, coefficients of variance, and reference ranges of her androgen measurements were fully described in our previous study. ${ }^{3}$ In this case, we used a free testosterone immunoassay instead of calculation of free testosterone because free testosterone immunoassay is quite common in Japan and is reported to be strongly correlated with calculation of free testosterone. ${ }^{4}$ Initial hormonal examination revealed her androgen levels to be extremely high. Insulin resistance was assessed using homeostasis model assessment of insulin resistance (HOMA-IR), which was calculated using the formula: fasting plasma glucose $(\mathrm{mg} / \mathrm{dL}) \times$ fasting insulin $(\mu \mathrm{U} / \mathrm{mL}) / 405$. With a HOMA-IR $>2.0$, she was diagnosed as being insulin-resistant. ${ }^{5}$ Adiponectin, an insulin-sensitizing adipocytokine which decreases with deposition of visceral fat ( $<8 \mu \mathrm{g} / \mathrm{mL}$ is considered abnormal), was also measured as a surrogate marker of insulin resistance. ${ }^{5}$

Table I Endocrine profiles of the patient

\begin{tabular}{ll}
\hline Hormonal parameters & Reference range \\
\hline Total testosterone & $<0.7$ \\
$\quad 4.59 \mathrm{ng} / \mathrm{mL}$ & \\
Free testosterone & $<1.0$ \\
$\quad 13.5 \mathrm{pg} / \mathrm{mL}$ & \\
DHEAS & $<3500$ \\
$\quad 4810 \mathrm{pg} / \mathrm{mL}$ & \\
Androstenedione & $<3.5$ \\
$\quad 19 \mathrm{ng} / \mathrm{mL}$ & $<10$ \\
LH & \\
$2.1 \mathrm{mIU} / \mathrm{mL}$ & $<10$ \\
FSH & \\
$3.22 \mathrm{mIU} / \mathrm{mL}$ & $<80$ \\
Estradiol & \\
$38.43 \mathrm{pg} / \mathrm{mL}$ & $\mathrm{FSH}, \mathrm{fl}$
\end{tabular}

Abbreviations: DHEAS, dehydroepiandrosterone sulfate; $\mathrm{FSH}$, follicle-stimulating hormone; LH, luteinizing hormone.
Table 2 Metabolic profiles of the patient

\begin{tabular}{ll}
\hline Metabolic parameters & Reference range \\
\hline FPG & $<100$ \\
$84 \mathrm{mg} / \mathrm{dL}$ & \\
IRI & $<10$ \\
$22.3 \mathrm{mIU} / \mathrm{mL}$ & \\
HOMA-IR & $<2.0$ \\
$\quad 4 . I$ & \\
Adiponectin & $>8.0$ \\
$4.62 \mu \mathrm{g} / \mathrm{mL}$ & \\
\hline
\end{tabular}

Abbreviations: FPG, fasting plasma glucose; IRI, fasting insulin; HOMA-IR, homeostasis model assessment of insulin resistance.

Transvaginal ultrasound examination revealed a solid mass in the right ovary, and the patient was referred to our hospital for further investigation and treatment. Magnetic resonance imaging performed at our hospital showed a solid mass in the right ovary and an immature uterus. The tumor was of moderate intensity on T1-weighted images and heterogeneously high intensity on T2-weighted images. Gadolinium-diethylenetriamine penta-acetic acid-enhanced T1-weighted images showed marked enhancement of the solid portion. Based on these findings, an androgen-secreting ovarian tumor was suspected. Exploratory laparotomy revealed a solid tumor in the right ovary without peritoneal implants or lymphadenopathy, and a right salpingo-oophorectomy was performed. Macroscopically, the tumor was an orange-colored solid mass, which caused partial rupture of the ovarian capsule (Figure 1A). Microscopically, the tumor cells contained small round nuclei and abundant vacuolated cytoplasm, and were arranged in nested and cord-like patterns (Figure 1B). The mass was diagnosed as a Sertoli-stromal cell tumor with intermediate differentiation. After the operation, menstruation occurred spontaneously but remained irregular, and although the patient's serum androgen levels declined, they remained above normal (Figure 2). Her hypertrichosis, adiponectin level, and HOMA-IR also did not improve. We recommended weight reduction to improve her insulin resistance, but she did not take action about her weight problem. Because of her poor compliance, we then settled for the second best strategy, ie, administration of an insulin-sensitizing agent. We chose pioglitazone because the maximal dose of metformin is limited to $750 \mathrm{mg}$ in Japan and its effect is less promising. Thiazolidinediones have been reported to be superior to metformin in reducing androgen levels. ${ }^{6}$ Two years of pioglitazone treatment at $15 \mathrm{mg} /$ day was effective, but did not completely resolve her refractory hirsutism, insulin resistance, or free testosterone level (Figure 3). However, she suddenly became lean for unexplained reasons, probably because she 

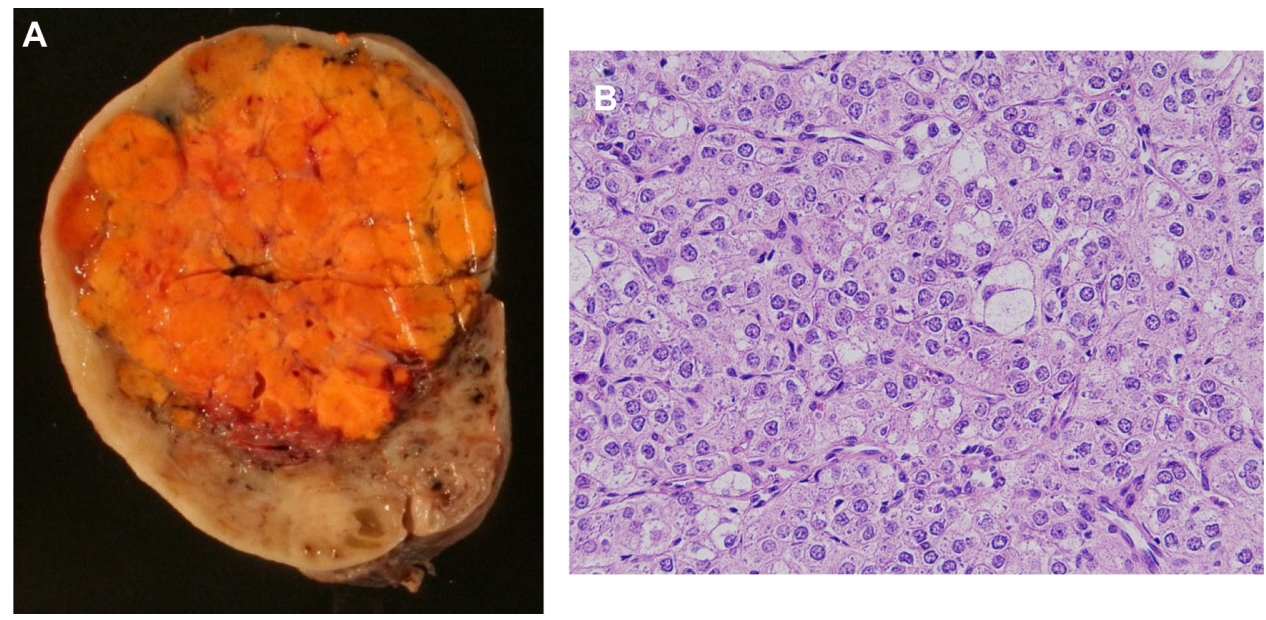

Figure I Resected specimen. (A) Macroscopic findings. The tumor was an orange-colored solid mass. (B) Microscopic findings.

Note: The tumor cells contained small round nuclei and abundant translucent cytoplasm, and were arranged in nested and cord-like patterns.

had had a change of heart about her weight problem. Loss of $12 \mathrm{~kg}$ of body weight (to $53 \mathrm{~kg}$, body mass index $21.2 \mathrm{~kg} / \mathrm{m}^{2}$ ) completely corrected both her hyperandrogenism and insulin resistance (Figure 3). The patient now takes no medication and is free of disease.

\section{Discussion}

In this report, we describe a case of hyperandrogenism caused by a Sertoli-stromal cell tumor of the ovary and secondary PCOS. Sertoli-stromal cell tumors of the ovary are rare neoplasms occurring mainly in patients younger than 30 years of age. ${ }^{7}$ Almost all of these tumors are confined to a unilateral ovary, and given the young age of these patients and the usual stage of the tumor, unilateral salpingo-oophorectomy remains



Figure 2 Postoperative changes in androgen levels.

Notes: After surgery, the patient's total testosterone level returned to normal, but free testosterone and dehydroepiandrosterone sulfate levels remained above the normal range. Following pioglitazone administration and weight reduction, androgen levels returned to normal. the most acceptable therapeutic strategy. The prognosis of Sertoli-stromal cell tumors is usually good and correlates with the stage and degree of differentiation. In our patient, the tumor was stage $1 \mathrm{c}$ and differentiation appeared to be intermediate; consequently, the prognosis was expected to be good. Earlier reports have noted that $11 \%$ of intermediately differentiated tumors are clinically malignant. ${ }^{7}$ Recurrence of malignant Sertoli-stromal cell tumors occurs relatively early, and recurrence is usually confined to the pelvis and abdomen, but distant metastasis to the lung, scalp, and supraclavicular lymph nodes has been reported. ${ }^{7}$ There has been no evidence of recurrence in our patient during 5 years of follow-up.

There are two aspects to this case that we find particularly interestingly. First, the causes of the patient's

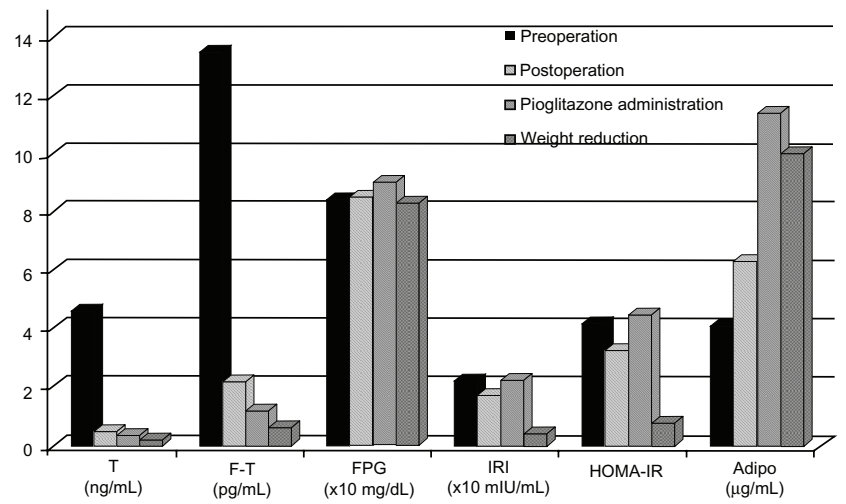

Figure 3 Effects of various treatment modalities on hormonal and biochemical parameters. Notes: After surgery, total testosterone levels returned to normal, but free testosterone levels remained above normal. Weight loss successfully resolved the patient's insulin resistance and hyperandrogenemia.

Abbreviations: F-T, free-testosterone; FPG, fasting plasma glucose; IRI, immunoreactive insulin; HOMA-IR, homeostasis model assessment of insulin resistance; Adipo, adiponectin. 
hyperandrogenism, ie, PCOS and the Sertoli-stromal cell tumor, can be superimposed. The diagnostic criteria for PCOS with other etiologies that can result in menstrual irregularity and hyperandrogenism should be excluded. ${ }^{8-10}$ Therefore, we omitted PCOS from consideration in the differential diagnosis of this patient. However, in cases like ours, the Sertoli-stromal cell tumor may cause secondary PCOS related to exposure of the ovary to high levels of androgens from puberty. Generally, we consider postoperative androgen levels to be an indicator of disease activity in androgen-secreting tumors. In our patient, androgen levels declined a week after surgery, but did not reach normal levels despite successful surgery. At this point, we considered the patient to have PCOS. Two months after the operation, free testosterone levels remained above normal. Because insulin-sensitizing agents are reportedly able to reduce androgen synthesis, ${ }^{11,12}$ pioglitazone was prescribed in an effort to normalize the patient's androgen levels, so as to treat her hirsutism and better monitor her for signs of recurrence. There is no need for concern about masking recurrence by treating hyperandrogenemia with pioglitazone, given that androgen production by neoplasms cannot be inhibited with insulin-sensitizing agents.

Second, the patient's weight reduction dramatically reduced her PCOS. Although ovulation disorders caused by hyperandrogenism in PCOS patients can often be treated effectively using insulin-sensitizing agents such as metformin and pioglitazone, ${ }^{13-15}$ our patient's free testosterone levels remained above normal after 2 years of treatment with pioglitazone. This may have been because the patient was overweight, and insulin resistance reduces levels of sex hormone-binding globulin, which binds and inactivates testosterone. In our case, pioglitazone alone did not completely resolve the patient's insulin resistance and sex hormone-binding globulin production, and weight reduction was a necessary part of her treatment. It is known that lifestyle modification can ameliorate hyperandrogenism in PCOS. ${ }^{16,17}$ However, there is a trend towards starting treatment of PCOS patients with drugs and without lifestyle intervention due to poor compliance with lifestyle modification. In addition, maintaining weight loss is difficult. It is quite rare that a case of PCOS resistant to an insulin-sensitizing agent can be completely cured by lifestyle modification alone. The lesson we learned from our experience is that we should strongly emphasize the importance of patient education concerning lifestyle modification.

In conclusion, this case provides us with useful knowledge that increases our understanding of the etiology and pathophysiology of PCOS. Lifestyle modification should be a first-line therapy for PCOS, although medication is easier and brings immediate benefits.

\section{Disclosure}

The authors report no conflicts of interest in this work.

\section{References}

1. Novak ER, Long JH. Arrhenoblastoma of the ovary. Am J Obstet Gynecol. 1965;92:1082-1093.

2. Franks S, McCarthy MI, Hardy K. Development of polycystic ovary syndrome: involvement of genetic and environmental factors. Int J Androl. 2006;29:278-285.

3. Baba T, Endo T, Ikeda K, et al. Distinctive features of female-to-male transsexualism and prevalence of gender identity disorder in Japan. $J$ Sex Med. 2011;8:1686-1693.

4. Moreno SA, Shyam A, Morgentaler A. Comparison of free testosterone results by analog radioimmunoassay and calculated free testosterone in an ambulatory clinical population. $J$ Sex Med. 2010;7:1948-1953.

5. Baba T, Endo T, Sata F, et al. The contributions of resistin and adiponectin gene single nucleotide polymorphisms to the genetic risk for polycystic ovary syndrome in a Japanese population. Gynecol Endocrinol. 2009;25:498-503.

6. Li XJ, Yu YX, Liu CQ, et al. Metformin vs thiazolidinediones for treatment of clinical, hormonal and metabolic characteristics of polycystic ovary syndrome: a meta-analysis. Clin Endocrinol. 2011;74:332-339.

7. Young RH, Scully RE. Ovarian Sertoli Leydig cell tumors: A clinicopathological analysis of 207 cases. Am J Surg Pathol. 1985;9: 543-569.

8. Zawadski JK, Dunaif A. Diagnostic criteria for polycystic ovary syndrome: toward a rational approach. In: Dunaif A, Givens JR, Haseltine F, editors. Polycystic Ovary Syndrome. Boston, MA: Blackwell Scientific Publications; 1992.

9. The Rotterdam ESHRE/ASRM-Sponsored PCOS Consensus Workshop Group. Revised 2003 consensus on diagnostic criteria and long-term health risks related to polycystic ovary syndrome. Fertil Steril. 2004;81:19-25.

10. Azziz R, Carmina E, Dewailly D, et al; Androgen Excess Society. Positions statement: criteria for defining polycystic ovary syndrome as a predominantly hyperandrogenic syndrome: an Androgen Excess Society guideline. J Clin Endocrinol Metab. 2006;91:4237-4245.

11. Arlt W, Auchus RJ, Miller WL. Thiazolidinediones but not metformin directly inhibit the steroidogenic enzymes P450c17 and 3betahydroxysteroid dehydrogenase. J Biol Chem. 2001;276:16767-16771.

12. Kempná P, Hofer G, Mullis PE, Flück CE. Pioglitazone inhibits androgen production in NCI-H295R cells by regulating gene expression of CYP17 and HSD3B2. Mol Pharmacol. 2007;71:787-798.

13. Ortega-González C, Luna S, Hernández L, et al. Responses of serum androgen and insulin resistance to metformin and pioglitazone in obese, insulin-resistant women with polycystic ovary syndrome. J Clin Endocrinol Metab. 2005;90:1360-1365.

14. Jungheim ES, Odibo AO. Fertility treatment in women with polycystic ovary syndrome: a decision analysis of different oral ovulation induction agents. Fertil Steril. 2010;94:2659-2664.

15. Tang T, Lord JM, Norman RJ, Yasmin E, Balen AH. Insulin-sensitising drugs (metformin, rosiglitazone, pioglitazone, D-chiro-inositol) for women with polycystic ovary syndrome, oligo amenorrhoea and subfertility. Cochrane Database Syst Rev. 2010;1:CD003053.

16. Huber-Buchholz MM, Carey DG, Norman RJ. Restoration of reproductive potential by lifestyle modification in obese polycystic ovary syndrome: role of insulin sensitivity and luteinizing hormone. J Clin Endocrinol Metab. 1999;84:1470-1474.

17. Moran LJ, Hutchison SK, Norman RJ, Teede HJ. Lifestyle changes in women with polycystic ovary syndrome. Cochrane Database Syst Rev. 2011;7:CD007506. 
International Journal of Women's Health

Dovepress

\section{Publish your work in this journal}

The International Journal of Women's Health is an international, peerreviewed open-access journal publishing original research, reports, reviews and commentaries on all aspects of women's healthcare including gynecology, obstetrics, and breast cancer. Subject areas include: Chronic conditions (migraine headaches, arthritis, osteoporosis);

Endocrine and autoimmune syndromes; Sexual and reproductive health; Psychological and psychosocial conditions. The manuscript management system is completely online and includes a very quick and fair peer-review system. Visit http://www.dovepress.com/ testimonials.php to read real quotes from published authors.

Submit your manuscript here: http://www.dovepress.com/international-journal-of-womens-health-journal 